\title{
Risky-Sexuality and the Perceptual Assessment of the Intervention Constituencies: A gender Analysis of Lagos' School-based Adolescents
}

\author{
Olatunji Babatola ${ }^{1}$ and Emily Ojukwu ${ }^{2}$
}

\author{
Dept. of Geography, University of Lagos, \\ Lagos, Nigeria \\ obabatola@unilag.edu.ng
}

\begin{abstract}
The inadequacies of the typical study designs and the parameters employed in the performanceassessment of adolescents' sexual-behavioural interventions in the context of HIV/AIDS, provoked this study. It examines risky-sexuality of gender-categorized adolescents; their access to intervention actors and relevance-ascription to existing interventions, classified by originating constituencies. Using a questionnaire administered by purposive-cum-random sampling techniques to final-year Senior Secondary School students, in Lagos, Nigeria, it collected information on parental backgrounds; personal sexuality attributes; exposure to agents-cum-instruments of sexual behavioural re-orientation; and personal assessment of benefitted interventions from the specified constituencies. Findings indicate that both genders which converge appreciably on some personal/parental attributes, contrast on riskysexuality attributes, and in their relative exposure to constituency-differentiated interventions. Statistical hypothesis shows both genders contrasting on relevance-ascription to intervention constituencies. The study conclusively canvassed for improvement in male-intervention attention, including extending the current analytical-purview to include correlate-analysis of relevance-ascription, and other concerns that broaden intervention-researches' usefulness.
\end{abstract}

Keywords: Adolescent, Interventions agents, Intervention Constituencies, Risky-sexuality.

\section{Introduction}

The emergence of HIV/AIDS as an international morbidity challenge accelerated the intensity and widened the dimensions of research on human sexuality by the different disciplines in the academic world. One of the major underpinning motives of the various researches was to identify possible windows of interventions through which both the infection and its epidemic can be effectively contained or managed. With reference to Nigeria, and in particular to Lagos state, official response to HIV/AIDS was rather late in-coming. This arose partly from the initial cynical disposition towards the bio-medical pronouncement of the incurability of HIV/AIDS' which seemed to conflict in varying degrees with the extant local positions on pathology (Caldwell, Orubuloye and Caldwell (1999)) and Babatola (20I2)).

Indeed the first major demonstration of the intention to combat HIV/AIDS infection with reference to its youth population was the inauguration of the Family Life and HIV/AIDS Education Programme (FLEP) in 2005 by the Lagos State Government (Lagos State Ministry of Education, Action Health Incorporated, Philliber Research Associates and the International Women's Health Coalition. (2006). As a programme, FLEP was conceived as a school-based intervention aimed among others at increasing the age of sexual debut as well as reducing the rate of HIV/AIDS infection among youths.

Cognizant of the relevance of parents and other differently-relevant actors in the home domain, and realizing also that a large percentage of the nonschooling adolescents interact in the home environment with the schooling ones, the government strategically included the mobilization of parents as part of FLEP (Lagos State Ministry of Education, Action Health Incorporated, Philliber Research Associates and the International Women's Health Coalition. (2006)). The strategy entailed the use of existing Parents/Teachers/Association (PTA) in schools to mobilize and enhance parents' capability to engage in effective home-based adolescent-focused sexuality intervention.

In essence, the home and school domains or constituencies were recognized and mobilized as complimentary partners in the task of adolescents' sexual behavioural re-orientation when the intervention commenced about a decade ago. However, given that adolescents are peculiarly characterized by experimental-cum-adventurous longing for sex, and also, given that sexual urge is a function of individuals' psycho-libidinous nature, which may vary (National Coalition for Sexual Health (20I3), Aji, Aji, Ifeadike, Emelumadu, Ubajaka, 
Nwabueze, Ebenebe, and Azuike (2013) etc.), the effectiveness achieved by the different intervention actors in the two constituencies respectively may vary. Indeed the revelation that the adolescents' pattern of HIV/AIDS infection in Lagos have assumed more of an oscillatory rather than a continuously declining trend (The Insight Health Consulting Limited (2009)), may be an indication that at least one of the two constituencies is under-performing.

Ironically, however, the sexuality-related statistics generally employed in assessing the measure of progress made with respect to sexual behaviuoral intervention among adolescents have their limitations in terms of both the dimensions and the in-depth assessment they convey. Specifically, being summary indices, they offer no clue as to which particular issues or actor(s) in either of the existing constituencies needed to be better addressed in order to fortify any intervention characterized by flagging results. Secondly, such interventionassessment statistics provide no information as to the extent to which the perceptual evaluation of the different intervention constituencies by the adolescents population agrees with the level of intervention- success portrayed by such statistics.

It is this observed gap in analytical framework of researches on adolescents' risky sexuality which informed the interest of this paper in analyzing adolescents' risky-sexuality and their perceptual assessment of the significant intervention constituencies in Lagos state, Nigeria. To achieve its aim, the paper will among others:

I. examine the extent to which similarities exist between the adolescent genders in terms of their personal and parental attributes that could in any way impinge on either their sexual behavior or the likelihood of its adjustment.

2. analyze the precedent and current risky sexuality profiles of the study population in the context of how they differ by gender.

3. examine the extent to which the two gender groups benefitted from access to the identifiable intervention agents in the two constituencies and the degree of such access.

4. determine the extent to which the two genders converge or diverge in their assessment of the positive impact of the two constituencies on their sexual behavior in recent times.

5. analyze the policy implication of the major findings for adolescent risky sexuality intervention improvement in Nigeria, particularly in Lagos state.

\section{Literature Review and Analytical Framework}

Interests in adolescent sexuality analysis originated in the context of pre-marital teenage pregnancies. A long list of researchers has focused on this issue. A few of the well-cited works in this domain of research includes Howard and McCabe (1990), Howard and Mitcheil (1993), Kirby (1992)

The advent of HIV/AIDS and the indictment of youths (Amazigo, 1997), that is, those within the $15^{\text {th }}$ and $24^{\text {th }}$ age brackets, for comparatively higher infection-vulnerable sexual practices has increased the dimensions of analysis on adolescent sexuality. Parsimoniously, the different issues addressed by researchers on adolescents' risky-sexuality in the context of HIV/AIDS may be categorized under three major thematic domains; which may be further subdivided. Studies which fall under the first major theme are basically baseline studies. Their main interest is to capture the prevailing sexual behavioural values and practices of a given population in order to determine their 'at-risk' level to HIV/AIDS infection; or, where possible, directly ascertain the degree of sero-positivity in that population. The list of published works on this theme gets longer almost on a daily basis. Prominent pioneers and subsequent exponents include Ogbuagu. and Charles (1993),, Adegbola, Babatola and Oni (1995) Adegbola and Babatola (1999), Anochie, and Ikpeme (200I) Makinde (2008) USAID (20I3), etc.

The second category of interests analyzes the factors and implications of youths' risky sexuality. Notable factors which have been identified include the experimenting and the adventurous tendencies of youths towards sexuality (Crockett, Raffaelli and Moilanen, (2003), disadvantaged socio-economic background and weak family intimacy and support (Santelli, Lowry, Brener, and Robin(2000), Yifru Berhan and Asres Berhan (2015)), - as well as the use of substance (Ryckman, (2008) and Stevens \& Cloete, (2009)).

A notable issue highlighted in the list of the consequences of the HIV/AIDS infection/epidemic with reference to the youths is the incidence of homes that are bereaved of either of the two parents or both and the socio-economic implications of orphans in a community. Numerous research works which have been carried out directly or tangentially on this theme include Booysen, Bachmann, Matebesi and Meyer (2004), Timko (20I I), Taraphdar, Rray, Guha, Haldar, Chatterjee, Dasgupta, Saha and Mallik (20II)

The third major dimension of HIV/AIDS research focuses on interventions which are designed to curtail the spread of either risky sexual behaviour or to ameliorate the consequences of the observed negative sexuality among population groups. One of the major sub-themes that has featured in this domain is the assessment of the degree of success of specific interventions, using a number of statistical parameters which include changes in the incidents of 
infection-prone sexual practices of the adolescent group in a population; the magnitude of newlyrecorded STI particularly HIV/AIDS among the youth; and the number of adolescents dying per thousand of the population due to HIV/AIDS.

Two things appear to be substantially lacking in the approach of research to the analysis of intervention to date. The first is that the outcomes which measure interventions' performance are sometimes presented without linking them to specific constituencies. Studies which linked them such as Kirby (1992) Anochie and Ikpeme (200I) Izugbara (2005), Makinde (2008) Akpabio, Michael, Asuzu, Fajemilehin, and Ofi (2009), Mukoma, Flisher, Ahmed, Jansen, Mathews, Klepp and Schaalma (2009), Mathews, Aarø, Grimsrud, Flisher, Kaaya, Onya, Schaalma, Wubs, Mukoma and Klepp (20I2), etc., rarely do so using study designs which permits a comparative relevance-assessment analysis of intervention actors either within a constituency or between identifiable constituencies.

The point being stressed here is that the typical designs employed by many studies analyzing adolescents' sexual intervention tend to overlook the implication which adolescents' subordination status may have on the degree of success attainable by individual intervention and endeavor to reflect that dimension in their assessment of intervention. Specifically, differences in the degree to which the adolescents' subordination culminates in authoritarian posture of the different actors in the two domains will likely affect the degree of success or improvement achieved by such interventions. Ironically, the commonly employed summary statistics on sexual-behaviuoral cum morbidity/mortality changes for gauging the performance level of HIV/AIDS interventions generally do not reflect the differential import of the superintending actors in the two domains.

The present study improves upon the extant study design indirectly. It examines the degree to which the adolescents, defined by gender, ascribed relevance to major home- and school-based actors, and the extent to which they value the input of the two constituencies in their sexual behavior and practices 'over the last one year' of the study. It is reasonable for example to assume that the home would contrast in some respects with the school setting, especially given that one is informal while the other, that is the school, is largely formal. It is not unlikely therefore, that differences in specific operational peculiarities of the two constituencies may contrast the genders in terms of the degree to which they appreciate services emanating from the two constituencies.
Analysis employing this paradigm has been very rare, particularly with respect to studies conducted on adolescent sexuality interventions in Lagos and indeed the entire Nigeria. Furthermore, apart from the question of authoritarian posturing of intervention actors, peculiar differences in the personal background attributes of the adolescents themselves may influence their perception and acceptance of either specific intervention measures or the methods of their administration. The implication of this is that any analysis which incorporates adolescents' perceptual assessment of the intervention components offers more relevant results, than those that exclude it; especially in the context of their intervention-feedback relevance. Helleve, Flisher, Onya, Matthews, Aaro and Klepp (20II) which incorporated an element of students' perception did so in the context of assessing their teachers only, excluding other actors even within that domain of intervention.

This paper on the other hand obtained from the adolescent beneficiaries their perceived relevance of specified intervention constituencies; in terms of how they have positively influenced their sexual behavior regardless of what official statistics depicts about the performance of such intervention. Such an analytical framework represents a more inclusive design, in the sense that it presents the results of interventions in the context of the perceived relevance-differentials of the major actors in the system, rather than relying solely on the traditional sexual-behavioural statistics in gauging and comparing intervention outcomes. More importantly, the design has a greater utilitarian capacity for identifying the nature and the degree of improvement required by each constituency, including what internal instrument or actors needed re-strengthening, in order to achieve sustained improvement by intervention efforts.

\section{Data and Method}

This study is a sub-set of a wider-purview research which compared risky sexuality and interventionrelated issues between adolescents in the Senior Secondary schools and youths in tertiary institution in Lagos State, Nigeria. The present section will address the methodological issues that are relevant to the collection of data on the target population of the present paper, that is, the Senior Secondary school students. Given that the Lagos State Government uses the 'Education Districts' method in streamlining the administration of her schools, the sampling process commenced with the purposive selection of three Education districts that give fair representation of the state, both in terms of its ethnographic mosaic and rural urban differentials. 
The first step therefore entailed a purposive selection of the set of Education Districts in Lagos. Schools were thereafter randomly selected from each of the selected education districts. To avoid serious gender imbalance the procedure assigned schools to be covered in the sampling exercise in such a way that three co-education schools, three male-only schools and three female-only schools were selected across the 6 Education districts covered. The next task was to enlist the approval of the school authorities after briefing them of the purpose of the research and submitting a copy of the questionnaire.

\section{The fieldwork procedure}

The original design which was to randomly select nine schools consisting of one male-only, one femaleonly and a co-educational institution in each of the 3 education districts purposively selected for the study was slightly compromised for the lack of a male-only senior secondary school in District 2. In that district, 2 co-education schools and one female-only school were sampled. Students in the final senior secondary class were the target population, in that they have the comparatively longest intervention duration, especially with regards to the school-based intervention. The strategy designed to obtain the samples of students was as follows. For each class the
Arabic numerals from I to ' $N$ ' corresponding to the number of students in that class register were written on small paper slips. The slips were folded and put together in a nylon sack that make up the sample space from which individual respondents were drawn independently, one, after the other, until the specified $20 \%$ target was obtained.

Table I illustrates the distribution of the sampled students by the selected education districts and gender. Slightly above $36 \%$ students, made up of $40.8 \%$ males and $59.2 \%$ females belong to District 2 . Districts 3 and 4 respectively constitute $34 \%$ and $29.1 \%$ of the respondents' population.

Table I: Profile of the Randomly Sampled Students' Population by Education Districts

\begin{tabular}{llll}
\hline Education District & Male & Female & Total (\%) \\
\hline District 2 & & & \\
I Male-only school & $\mathrm{None}$ & $\mathrm{Na}$ & - \\
2 Female-only School & $\mathrm{Na}$ & $4 \mathrm{I}$ & $4 \mathrm{I}(34.2)$ \\
3. Co-education schools & 49 & 30 & $79(65.8)$ \\
Sub-total & $49[40.8]$ & $7 \mid[59.2 \%]$ & $120(36.1)$ \\
District 3 & & & \\
I Male-only school & $4 \mathrm{Na}$ & $4 \mathrm{I}(36.3)$ \\
2 Female-only School & $\mathrm{Na}$ & $4 \mathrm{I}$ & $4 \mathrm{I}(36.3)$ \\
3. Co-education schools & 26 & 5 & $3 \mathrm{I}(27.4)$ \\
Sub-total & $67[59.3]$ & $46[40.7]$ & $113(34.0)$ \\
District 4 & & & \\
I Male-only school & 39 & $\mathrm{Na}$ & $39(39.4)$ \\
2 Female-only School & $\mathrm{Na}$ & 20 & $20(20.2)$ \\
3. Co-education schools & 26 & $\mathrm{I}$ & $40(40.4)$ \\
Sub-total & $65[65.6]$ & $34[34.4]$ & $99(29.1)$ \\
Total & $18 I(54.5)$ & $15 \mathrm{I}(45.5)$ & 332 \\
\hline
\end{tabular}

The sampled students were taken through the questionnaire and were thereafter given the time to complete the questions. Over 350 questionnaires were administered of which 332 were found admissible for coding and analysis.

Research Instrument. Each questionnaire obtained information on a number of themes which include: students' personal attributes; parental characteristics; precedent and present sexual practices; the profile of home and school-based intervention agents/actors and degree of adolescents' exposure to them in both constituencies. It also obtained information on how their sexuality practices have changed in the last one year and also in the past 6-months. It obtained their personal rating of the role played by the two 
constituencies respectively in their positive sexual behavioural adjustments within the last one year.

\section{Analysis of Research questions}

The paper, using personal and selected parental/background attributes, compares the extent to which the study population, classified by gender, exhibit degrees of similarities. It operationalizes changes in risky-sexuality over time by comparing the degree of riskiness portrayed by the age when the first lover was contracted as well as the age at first sexual event on the one hand, vis-à-vis the degree of riskiness portrayed by the current sexuality variables.

Analysis of the issues on intervention among others compares the degree to which the two genders are exposed to sexuality intervention from actors/agents in the two constituencies using multichoice frequency analysis. Further, it employs the cross-tabulation analyses to examine the extent to which the pattern of positive approval of the home intervention corresponds with that for the school constituency. To do this, the responses to the questions on whether or not they considered that interventions respectively from the two domains had impacted their sexual behavior/practices positively in the last one year were employed. Those who said 'NO' to each of the two questions were scored zero (0), those who were not sure, being not negative were scored ' $I$ ', while those who ascribed positive impact to either intervention were scored ' 2 '. These categorized responses to the two questions were first cross-tabulated to obtain the extent to which they correspond or differ. It then employed the Students' t-statistical test to determine whether significant differences exist between the two genders on how they perceived the intervention relevance of the two constituencies on their sexual behavioural adjustment in the last one year of the study. The different findings were then exhaustively discussed.

\section{Results}

Table 2 analyses the socio-demographics, including the parental characteristics of the study population. Males constitute $54.5 \%$ of the sampled population while the females are $45.5 \%$. The age structure shows that the males are significantly older than their female counterparts. Over $49 \%$ of the males belong to the 17-20 age-group, to which only $27.2 \%$ of the females belong. Indeed, the calculated mean age difference between the male $(x=16.60)$ and the female ( $=15.99$ year) of 0.60 years is found to be significance at $p=.000$ level.

The profile of religion/denominational adherence shows that Islam constitutes the largest single block on both sides. Among male adolescents, 45.3\% profess Islam against $47 \%$ among the females. The other lager groups among the males are the Pentecostal $(22.7 \%)$ followed by the Catholics. Slightly less than $4 \%(3.9 \%)$ of males and $0.7 \%$ of females respectively.

Table 2: Socio-demographic and parental backgrounds of study population.

\begin{tabular}{lllll}
\hline Major - Characteristics & \multicolumn{2}{c}{ Males } & \multicolumn{2}{c}{ Females } \\
& No (18I) & $\%$ & No (151) & $\%$ \\
\hline Age & 39 & 21.5 & 55 & 36.4 \\
I3-15 & 53 & 29.3 & 55 & 36.4 \\
I6 & 89 & 49.2 & 41 & 27.2 \\
I7-20 & 7 & & & \\
Religion and Denomination & 29 & 3.9 & 1 & 0.7 \\
None & 6 & 16.0 & 22 & 14.8 \\
Catholic & 82 & 3.3 & 9 & 6.0 \\
Protestant & 41 & 45.3 & 70 & 47 \\
Islam & 5 & 22.7 & 37 & 24.8 \\
Pentecostals & 11 & 2.8 & 6 & 4.0 \\
African Worship & & 6.1 & 4 & 2.7 \\
Others & 135 & & & \\
Parents' Currently- Living Status & 12 & 75.4 & 134 & 89.3 \\
Both parents alive & 22 & 6.7 & 4 & 2.7 \\
Father - only alive & 10 & 12.3 & 8 & 5.3 \\
Mother-only alive & & 5.6 & 4 & 2.7 \\
Neither parents alive & 99 & & & \\
Current living arrangement & 21 & 54.7 & 81 & 53.6 \\
Living with either or both parents & 24 & 11.6 & 10 & 6.6 \\
Living with other relations & & 13.3 & 17 & 11.3 \\
Living with guardians & & & & 2694 \\
\hline
\end{tabular}

http://aps.journals.ac.za 


\begin{tabular}{|c|c|c|c|c|}
\hline Living with others & 37 & 20.4 & 43 & 28.5 \\
\hline \multicolumn{5}{|c|}{ Educational Level of Parents- Father } \\
\hline None & 9 & 5.3 & 7 & 4.8 \\
\hline Primary & 24 & 14.1 & 13 & 8.9 \\
\hline Secondary & 83 & 48.8 & 73 & 50.0 \\
\hline University & 35 & 20.6 & 29 & 19.9 \\
\hline University/Equivalent & 16 & 9.4 & 20 & 13.7 \\
\hline Postgraduate & I & 0.6 & 2 & 1.4 \\
\hline \multicolumn{5}{|c|}{ Educational Level of Parents- Mother } \\
\hline None & 22 & 13.2 & 5 & 3.4 \\
\hline Primary & 31 & 18.6 & 21 & 14.3 \\
\hline Secondary & 76 & 45.5 & 79 & 53.7 \\
\hline University & 19 & $1 \mathrm{l} .4$ & 31 & 21.1 \\
\hline University/Equivalent & 9 & 5.4 & 3 & 2.0 \\
\hline Postgraduate & 9 & 5.4 & 5 & 3.4 \\
\hline \multicolumn{5}{|c|}{ Parents Occupation - Father } \\
\hline None & 17 & 10.3 & 6 & 4.1 \\
\hline White Collar & 14 & 8.5 & 12 & 8.2 \\
\hline Skilled Professional & 62 & 37.6 & 61 & 41.5 \\
\hline Unskilled/Artisan & 12 & 7.3 & 17 & 11.6 \\
\hline Sale/Biz & 26 & 15.8 & 35 & 23.8 \\
\hline Others & 33 & 20.0 & 14 & 9.5 \\
\hline \multicolumn{5}{|c|}{ Parents Occupation- Mother } \\
\hline None & 20 & 11.9 & II & 7.5 \\
\hline White Collar & 6 & 3.6 & 10 & 6.8 \\
\hline Skilled/Professional & 32 & 19.0 & 26 & 17.8 \\
\hline Unskilled/Artisan & 9 & 5.4 & II & 7.5 \\
\hline Sale/Biz & 76 & 45.2 & 83 & 56.8 \\
\hline Others & 25 & 14.9 & 5 & 3.4 \\
\hline \multicolumn{5}{|l|}{ Family type } \\
\hline Monogamous & 140 & 78.2 & 118 & 78.7 \\
\hline Polygamous & 36 & 20.1 & 31 & 20.7 \\
\hline Others & 3 & 1.7 & 1 & 0.7 \\
\hline
\end{tabular}

profess no specific religion. Some of the respondents also profess traditional religions. Specifically $2.8 \%$ of males and $4.0 \%$ of females belong to this category.

The currently-alive status of adolescents' parents shows that those having both parents alive are in the majority. The percentage of females (89.3\%) in this category exceeds that of the males $(75.4 \%)$ by close to $14 \%$. For the other categories which reflect the death of one of the two parents or both, the percentages of affected males generally double that of the females.

Current domicile arrangement shows that the single largest percentage of males $(54.7 \%)$ and females $(53.6 \%)$ live will both parents. More of males (II.6\%) live with other relations than their female (6.6\%) counterparts. Both groups exhibit close similarity in the population of their members living with guardians. Exactly $28.5 \%$ of the female group lives with motley of summarized benefactors tagged 'others' in contrast with $20.4 \%$ of the male counterparts.
The education status of parents shows considerable degree of similarities. For both genders, adolescents whose dads and mums have the Secondary School education are in the modal group followed by the University, the Primary School and, the Universityequivalent qualifications in that order of diminishing proportions. Exactly $48.8 \%$ and $50.0 \%$ respectively of males and females have fathers with Secondaryschool education which are reasonably close to $45.5 \%$ and $53.7 \%$ of the respective genders having mothers with the same educational qualification. Analysis of parents' occupation shows that the two genders contrasts marginally when either of the two parents is considered separately. In other words, the occupation structure of the adolescent males' dads resembles that of the females; while they contrast appreciably with the occupational patterns of their respective mothers.

On the fathers' side, the skilled professionals constitute the modal population group. $37.6 \%$ and $41.5 \%$ respectively of the male and female 
adolescents have skilled professional dads. The next ranking category for males is those with their dads in 'Other occupations' (20\%), while for the females it is Sales/business fathers (23.8\%). Interestingly enough, the Sales/business group ranked third (15.8\%) as fathers' occupation for the adolescent males. Both the percentages as well as the ranks of other occupations of fathers for both two genders show much similarity.

Mothers' occupation profile, as noted above, contrasts significantly with the profile of dads' occupations. For both adolescent genders, mothers in the sales/business constitute the modal group, being $45.2 \%$ of the males and $56.8 \%$ of their female counterparts. Next in importance are the mums in the skilled/professional occupations. The category with the least occupation for the female adolescent is the 'Others' group (3.4\%), while among males it is the white collar occupation (3.6\%).

Family-type pattern shows that majority of them regardless of their gender originate from monogamous family setting. It appears to be the foremost variable on which the two genders show the maximum similarity.

Precedent and current sexuality: Table 3 compares the two genders with respect to their precedent and current risky sexual behaviour, relying on two variables respectively for each of the two reference times. Age at which the first love-related friendship was contracted shows that a far larger percentage of males had their first lovers at earlier ages than their female counterparts. Specifically, close to $29 \%$ of males had their first lovers between ages 10 and 13 , compared to the females which had only $8.2 \%$ in that category. Those who moderately delayed contracting their first lovers commenced friendship between ages 14 and 16. They constitute the modal categories for both genders; consisting of $41.3 \%$ males and $60.8 \%$ females. Slightly above $6 \%$ of those who declined information on this variable are females compared to 4. $1 \%$ adolescent males. Those in the 'Not Applicable' group are those who claimed not to have contracted any lover-partner to date. They constitute $4.7 \%$ males and $6.2 \%$ of females. The proportion of those who declined information is higher among the female $(I 5.9 \%)$ than the males $(9.3 \%)$. The pattern corroborates findings of earlier researchers such as Clark Kabiru and Zulu (20II) of the tendency for underreporting of sexuality event by female in contrast to over-reporting by the males.

The pattern observed with the 'age of contracting the first boy/girlfriend is somewhat replicated by the age at first sexual intercourse, except that those who declined to give the specific age constitute the modal class for both genders, involving $30.7 \%$ of males and $59.4 \%$ of females. Analysis of those who gave specific ages shows that the modal class among males consists of those who moderately delayed their first sexual intercourse till the $17^{\text {th }}$ and $19^{\text {th }}$ age brackets. Those classified as 'probably uninvolved' were those who though withheld information about their sexual debut, but however claimed to have contracted first love-related friendship in the past.

Table 3 Precedent and Current Risky - Sexuality Variables

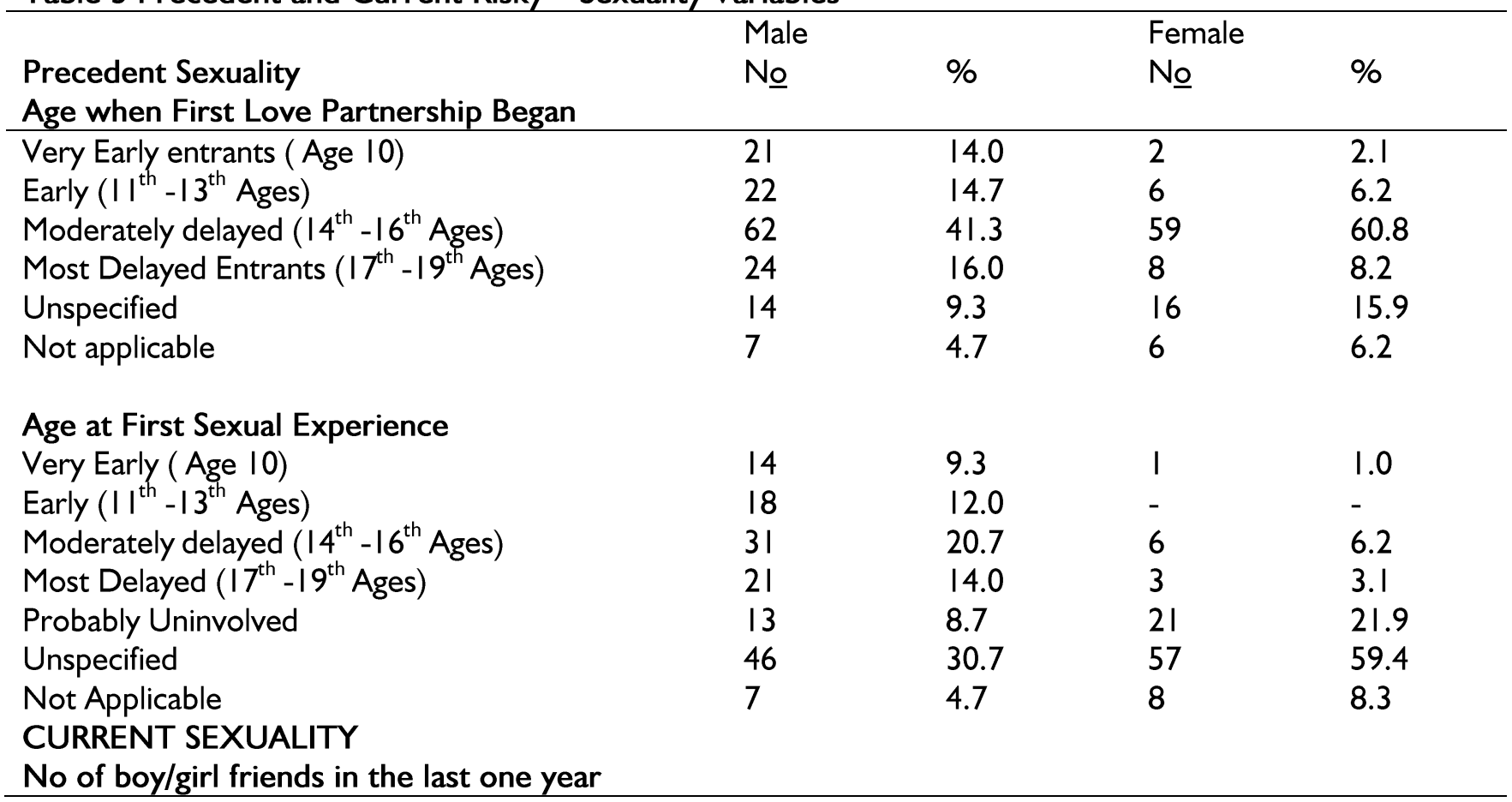




\begin{tabular}{lllll}
\hline None & 42 & 28.0 & 22 & 22.7 \\
Low partnership (I-2) & 48 & 32.0 & 36 & 37.1 \\
High Partnership (3-4) & 17 & 11.3 & 3 & 3.1 \\
Very High partnership (5+) & 16 & 10.7 & 2 & 2.1 \\
Unspecified & 2 & 1.4 & 1 & 0.7 \\
Not applicable & 25 & 16.7 & 33 & 34.0 \\
Sexual partners in the last one year & & & & \\
$0-1$ & 30 & 16.6 & 54 & 35.8 \\
$2-3$ & 25 & 13.8 & 5 & 3.3 \\
$4-5$ & 32 & 17.7 & 9 & 5.9 \\
$6+$ & 11 & 6.1 & 2 & 1.3 \\
Unspecified & 14 & 7.7 & 26 & 17.2 \\
Not applicable & 68 & 37.6 & 55 & 36.4 \\
\hline
\end{tabular}

Current Sexuality. Analysis of the current sexuality trait examines the number of lovers or boy/girl friends had in the last one year as well as the number of sexual intercourse-partners over the same period. The 'number of love-partners-had in the last one year' shows that majority of those who are currently in relationship have concurrently either 1 or 2 partners; $32 \%$ of males compared to $37.1 \%$ of their female counterparts are in that category. $28 \%$ and $22.7 \%$ respectively of male and female respondents that once had love partners currently do not have any. The proportion of females $(34.0 \%)$ who claimed to have had no love-partner ever, more than doubled the percentage $(16.7 \%)$ recorded by the males.

A comparison of the age when relationship with the first lover commenced and the number of those who currently have boy-/girl-friends shows that there is a decrease in the proportion of those that currently have boy/girlfriends. Indeed a very wide percentage gap exists between the sums of those who responded as "Not applicable" to the question on when the first boy/girl-friend was contracted and those who under the current love-partnership claimed "No partners" or "Not applicable". This shows a drop in the proportion of those currently in love relationship. For males $44.7 \%$ are currently partner-less compared to $4.7 \%$ who claimed to not have had any first-ever love partner. For the females it was $56.7 \%$ to $6.2 \%$.

Response to the question on the number of sexual partners in the last I year shows that those with one sexual partner constitutes the single largest group among the females, while those in the 4 to 5 sexual partners (I7.7\%) constitute the male's modal class. Adolescents with I or no sexual partner ranks next to the 4-5 partners (16.6\%) among male, followed by those who had 2 and 3 partners (13.8\%). Those who declined response were $37.6 \%$ and $36.4 \%$ respectively of the both population groups.

The observed reduction in the degree of exposure to risky-sexuality, using the current sexuality parameters as the gauge, may be an outcome of sexual behaviuoral-intervention which in this study is categorized into the home and school constituencies. The next section therefore examines the extent to which the two adolescent groups respectively acknowledged the role of home- and school-based actors in the entire process of intervention that culminated in their current sexual behaviour pattern in the last one year.

Table 4 shows the specified actors or the agents of sexual behavioural reorientation in the two intervention domains. The first section (A) summarizes the array of home-based personalities and agents that are acknowledged to be involved by both genders in the various sexual reorientation interventions process directed at them. $30.6 \%$ of adolescent male and $11.9 \%$ of their female counterparts did not ascribe positive impact to any of the existing home-based agents in their sexual behavior over the last one year. Those classified as 'Others only' in the home setting constitute the most important intervention agents for the males, $25 \%$ of adolescent males claim to have intervention talks from this amorphous group. 'Parents only' (11.7\%) ranks next in descending order of importance to the 'Others only' as males intervention benefactors. 'Relations and others only' (7.8\%), 'Parents with others only' (7.8\%) and 'Relations only' (4.4\%) follow in that descending order of benefactorrelevance to the adolescent males. The females' pattern contrasts somewhat. The modal group of intervention beneficiaries (3I.8\%) is those who acknowledged 'Parents-only' intervention. Next to this group are those who acknowledge the role of 'Parents and relations' (14.6\%); 'Parents and others only' (3.5\%). Those who acknowledge the support of the entire three home-based intervention actors are somewhat similar for the two genders being $5.0 \%$ of males and $5.3 \%$ of females. 
Table 4: Comparative Access to Agents/Channels of Sexuality Intervention (Home/School domains)

\begin{tabular}{|c|c|c|c|c|c|}
\hline \multirow{2}{*}{\multicolumn{2}{|c|}{$\begin{array}{l}\text { Home-based intervention } \\
\text { Intervention Actors/agents }\end{array}$}} & \multicolumn{2}{|l|}{ Male } & \multicolumn{2}{|c|}{ Female } \\
\hline & & Noo & $\%$ & № & $\%$ \\
\hline None & & $55^{-}$ & 30.6 & $29^{-}$ & 19.2 \\
\hline Parents only & & 21 & 11.7 & 48 & 31.8 \\
\hline Relations only & & 8 & 4.4 & 11 & 7,3 \\
\hline Others only & & 46 & 25.6 & 10 & 6.6 \\
\hline Parents and Relation only & & 11 & 6.1 & 22 & 14.6 \\
\hline Parents and Others only & & 14 & 7.8 & 18 & 11.9 \\
\hline Relations and Others only & & 16 & 8.9 & 5 & 3.3 \\
\hline $\begin{array}{l}\text { Parents, Relations and Others } \\
\text { School-based Intervention }\end{array}$ & & 9 & 5.0 & 8 & 5.3 \\
\hline Intervention actors/agents & & No & $\%$ & No & $\%$ \\
\hline Class Teacher & & 45 & 24.9 & 18 & 11.9 \\
\hline School Counsellors & & 55 & 30.4 & 101 & 66.9 \\
\hline $\begin{array}{l}\text { Adolescent Sexuality } \text { Risk } \\
\text { Persons }\end{array}$ & Resource & 12 & 6.6 & 10 & 6.6 \\
\hline Peer Educators & & 10 & 5.5 & 15 & 10 \\
\hline Others & & 22 & 12.1 & 11 & 7.3 \\
\hline Missing & & 37 & 20.4 & - & - \\
\hline
\end{tabular}

A greater proportion of females than males seems to value the school-based interventions in terms of having had positive influence on their sexual reorientation in the last one year. For example, 20.4\% of the males could not pin-point any school-based agent that are very relevant to them in the last one year, while no female held such a view. For both genders, the school counsellor is acknowledged as the most relevant actor in the school domain. The proportion of the females which acknowledge this (66.9\%) far outweighs that of the males (30.4\%) who said so. Next to the counsellor is the Class teacher (male $=24.9 \%$ and female $=11.9 \%$ ), followed by the 'Resource persons on Adolescent Sexual and Reproduction Health', to which 6.6\% respectively of both genders ascribed positive relevance. The other acknowledged intervention is 'Peer education'. More of females (10\%) than Males (5.5\%) acknowledged this channel.

So far, the pattern of acknowledged-relevance of the actors in the two domains would give the impression that the acknowledged-relevance of the home constituency is inferior to that of the school. The next analysis explores this idea further, to determine the extent to which the patterns of relevance-ascription to the two constituencies by the two genders are similar, or dissimilar using the crosstabulation analysis.

Table 5 cross-analyses the perception of both genders on whether or not the home and the school constituencies have assisted them in making positive http://aps.journals.ac.za adjustment in their sexual behaviour in the last one year. The general pattern which combined responses of both gender shows that II.4\% claimed to have benefitted no positive impact on their sexual behaviour from the home constituency in the last one year. Nearly twice that percentage $(22.3 \%)$ gave a similar verdict about the school. Comparatively, $57.8 \%$ ascribed positive influence to the home, while $59.9 \%$ did so for the school. $30.7 \%$ and $17.8 \%$ respectively were unsure of the impact of the home and the school.

Further details in the cross-analysis show that $23.7 \%$ of those (38) who ascribed 'no benefit' to home interventions, made similar claim about the school. $71.1 \%$ of them applauded the impact of the school intervention with only $5.3 \%$ of them being unsure of the school intervention relevance. Those who admitted (192) that home has positively impacted their sexual life demonstrate certain subcategorical peculiarities. $18.2 \%$ of them claimed that the school impacted no positive influence on their sexuality; $62 \%$ claimed that the school was indeed helpful, while $19.8 \%$ of them were unsure of the impact of the school. $29.4 \%$ of those (102) who were unsure of the home's positive influence, categorically claimed that the school had 'no positive' influence on them. $52 \%$ of them ascribed positive impact to schools, while $18.6 \%$ of them were likewise unsure of the relevance of the schools' intervention. 
A column-wise analysis of the table shows that of the $74(22.3 \%)$ that adjudged the schools' intervention as not relevant, $12.2 \%$ of them also adjudged the home likewise. $47.3 \%$ claimed the home impacted them positively, while $40.5 \%$ were unsure of the homes' intervention. Of those (199) who ascribed positive influence to the school intervention $13.6 \%$ claimed the home did not impact them positively,
$59.8 \%$ adjudged the home as positive, while $26.6 \%$ $3.4 \%$ who professed the irrelevance of the home, were neutral, not being sure of the homes' relevance. The last group, that is, those (59) who were unsure of schools' intervention relevance breaks down into: $64.4 \%$ who believe the home impacted them positively, and $32.2 \%$ who were not sure of its relevance.

Tables 5(a-c): Cross-Comparative Analysis of Home and School Sexuality Interventions

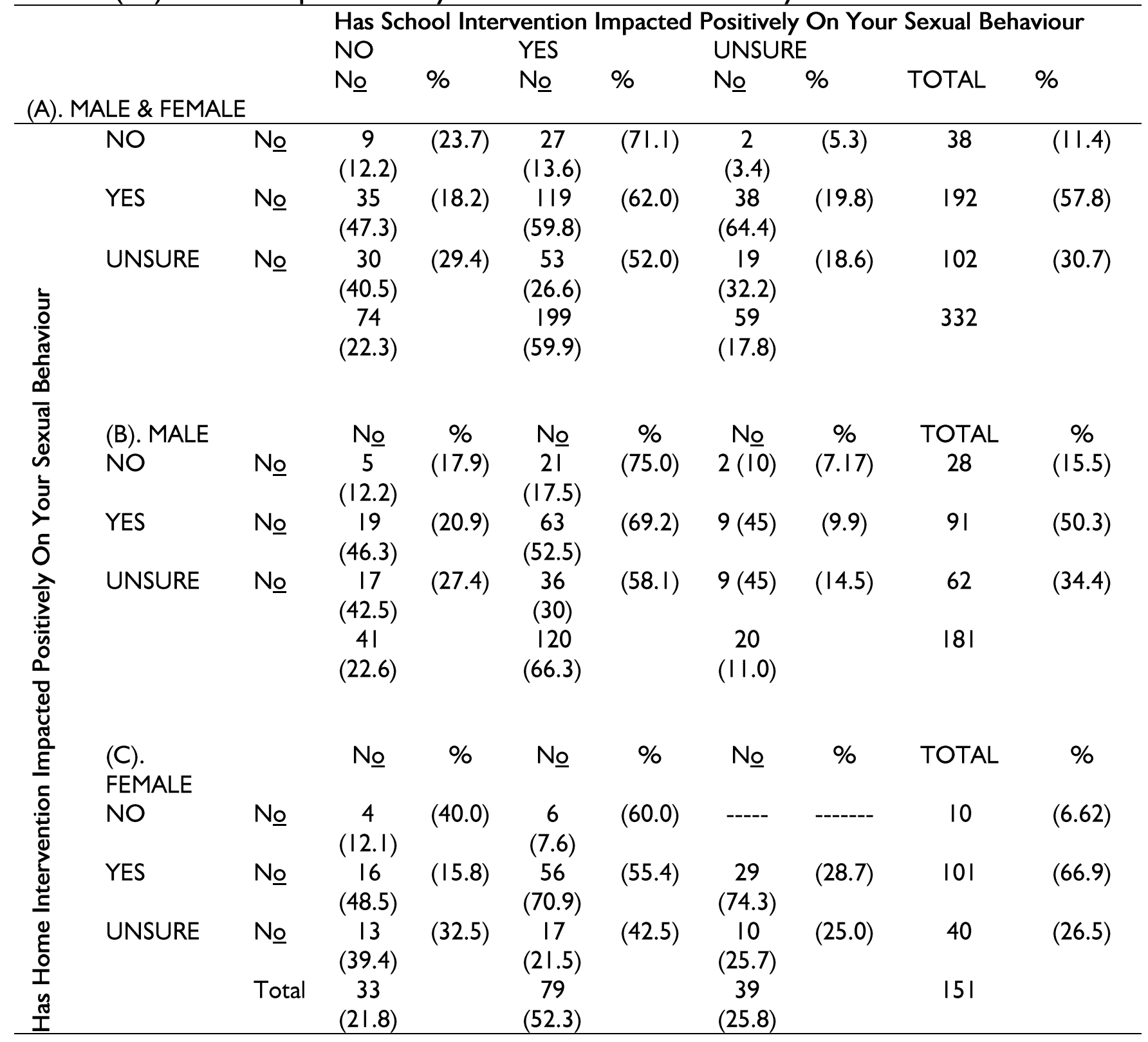

Emerging facts from the observed pattern above suggests that the school appears to enjoy a marginally higher approval rating in the combined analysis involving both genders. Sub-tables $5 b$ and $5 c$ show the individual pattern of approval and disapproval respectively by the two genders. For the sake of brevity, however, the analysis focuses solely on the sub-category which ascribed positive impact to the two constituencies.
Table $5 \mathrm{~b}$ shows that $50.3 \%$ of the (9I) males ascribed positive influence to the home constituency compared to $66.3 \%$ of them (120) that ascribed similar influence to the school intervention. Comparatively, of the 9I males which gave positive approval to the home impact $69.2 \%$ applauded the school intervention effort. The converse analysis on the other hand shows that of the 120 males who 
applauded the school intervention only $52.5 \%$ applauded the home intervention, $17.5 \%$ disapproved home-based intervention, while 30\% were unsure of its benefit.

Further analysis of Tables $5 b$ and $5 c$ shows that a higher percentage of females (66.9\%) than males $(50.3 \%)$ ascribed positive relevance to the home constituency. Likewise, a comparatively lower percentage of females $(52.3 \%)$ than males $(66.3 \%)$ on the other hand ascribed positive impact to the school-based interventions. Of the 101 female respondents that applauded home-based intervention $55.4 \%$ similarly applauded the school intervention, $15.8 \%$ gave a negative opinion, while $28.7 \%$ were unsure of the personal relevance of the school intervention.

Of the $79(52.3 \%)$ females who ascribed positive influence to schools, $70.9 \%$ of them also appreciate the impact of the home constituency, $7.6 \%$ disapproved of it, while $52.3 \%$ were unsure of the home impact. Clues from the analyzed statistics show that while a greater proportion of females tend to show higher positive assessment of the home in preference to the school constituency, the converse is the case among their male counterparts. It is however not very clear if the observed differences in the patterns of preferences by the two genders for the home and school interventions are significant or not. This is examined in the next section.

Table 6 specifically presents the results of the differential assessments of the two constituencies by the two population groups using the student's t-test. It shows whether or not the observed differences in their assessment of the two constituencies could be described as a chance occurrence, or be adjudged as reflecting the true occurrence in the larger adolescent population to which they belong. Obtained results show that males have a lower mean ascribed-relevance value (I.348) than the females (I.603) in their assessment of the home domain. The result gave a $t$ value of -3.390 which is statistically significant at the $\mathrm{P}=.00 \mathrm{I}$.

Table 6. T-test Parameter Results of Male-Female Assessment Of Home And School Domain Relevance In Sexual Comportment

\begin{tabular}{|c|c|c|c|c|}
\hline \multirow{2}{*}{$\begin{array}{l}\text { Test Parameters } \\
\text { Test Parameter }\end{array}$} & \multicolumn{2}{|c|}{ Home Intervention } & \multicolumn{2}{|c|}{ School Intervention } \\
\hline & Male & Female & Male & Female \\
\hline $\mathrm{N}$ & 181 & $|5|$ & 181 & 15 \\
\hline Mean & 1.348 & 1.603 & 1.436 & 1.305 \\
\hline SD & .734 & .612 & .838 & .808 \\
\hline t-statistic & 3.390 & & 1.450 & \\
\hline Df & 330 & & 330 & \\
\hline$P$ & .001 & & .148 & \\
\hline \multicolumn{3}{|c|}{$\begin{array}{l}\text { Decision: Significant differences exist between the two genders in } \\
\text { their perceived relevance of the home-based intervention to the } \\
\text { positive adjustment in their sexual practices in the last one year. }\end{array}$} & \multicolumn{2}{|c|}{$\begin{array}{l}\text { No significant differences exist between the two genders in } \\
\text { their perceived relevance of the school-based intervention to } \\
\text { the positive adjustment in their sexual practices in the last one } \\
\text { year. }\end{array}$} \\
\hline
\end{tabular}

The implication of the significant difference in the obtained t-test result between the two genders is that the higher degree of approval of the home constituency by the female may not be described as a chance occurrence. It reflects the true perceptual difference between the two genders, on how the home constituency had impacted them towards positive sexual re-orientation within the last one year of the study. The t-test result for the school constituency on the other hand, shows that the males' mean approval value (I.436) is only marginally higher than the females' (1.305). The difference in the mean scores yielded a t-value of 1.450 and $p$ value of .148, which is highly insignificant. In other words, the observed differences between them in respect of the school-based intervention did not exhibit statistical significance. The obtained result might have been an accidental result rather than a true or valid difference between the two population groups, with regard to how they value the impact of the school intervention on their sexual behavioural re-orientation within the last one year of the study.

\section{Discussion of the results}

Analysis of the data shows that while a number of personal and parental background attributes appear to significantly differentiate males from the females in varying degrees, others show an appreciable degree of harmony between them. The list of harmonizing variables include 'religion', 'current domicile arrangement', 'fathers education', and 'family type', while 'age, 'Parents-alive' status 'mothers' education', 'fathers' and 'mothers' occupations respectively exhibit differentiating tendencies between the two genders. Analysis of the connections between the personal/parental variables and the degree of intervention-benefits admittedly appropriated from the two constituencies is deliberately downplayed in 
this analysis, being outside its primary objectives. Nevertheless, it appears as if the differences in the degree of access to living parents whether single or both, for which the males are highly disadvantaged, may explain their significantly lower relevanceassessment rating of the home constituency. This corresponds with Biddlecom, Awusabo-Asare, and Bankole's (2009) findings on the critical role of parents in home-based communication.

The difference observed in the precedent and current sexuality traits conform to the popular finding by Clark., Kabiru and Zulu (20I I) that males tend to exaggerate self-reporting sexual attribute, while the female contrastingly tend to under-report. Notwithstanding this general observation, the males exhibit younger commencement ages both with reference to the age at which the first lover was contracted as well as the time of sexual debut. The record of the number of 'boy-/girl-friend had in the last one-year' also shows that males exhibit a higher at-risk level than the females. The same pattern characterizes the number of sexual partners in the last one year.

A comparison of the levels of actual and implied sexual activity by the two variables, 'age at the first sexual event' and the 'proportions of those who had had sexual partners or intercourse in the last one year' gave the impression that sexual activity had declined among the population. This observation prompted the analysis which examined whether, the adolescent population, classified by gender, would ascribe the changes in their sexual behavioural practices to interventions from either of the two domains, and if so to what extent?

The assessment of the relative effectiveness of the interventions by both genders shows that the male gender was relatively disadvantaged, given the degree to which they admittedly accessed the available interventions through the existing resource-agents in the two domains. The modal group among them, for example, were those who claimed to have not benefited on sexuality intervention from any of the existing home-based resource persons, the next category among them consisted of those who patronized the non-descript group called 'others' whose identity as well as the positive usefulness of their sexual education may not be accurately determined. The modal class of the female gender on the other hand ascribed home sexuality intervention to 'parents only' followed by those who specified the 'parents and relations only' and then the 'parents and others only' in that diminishing order of importance.

In the school domain where the counsellors are acknowledged as the major resource persons respectively by both genders, the percentage of males which ascribed such importance to them is comparatively lower than a half of the females that did so. On the other hand the appreciable degree of relevance-ascription to the non-descript group called 'Others' by the males, which occurred at home also occurred in the school domain. The fact that these 'others' who are neither parents nor relations in the home setting, just as they are neither counsellors nor class teachers, nor adolescent sexuality experts in the school domain, gives an indication of the significantly poorer exposure of the adolescent males to the benefit of existing sexuality intervention in both domains to date. This implies that the degree of importance attached by the adolescent males to the interventions or, the importance attached to them by the actors in the two constituencies appears rather marginal vis-à-vis the position of their female counterparts.

The males' poorer appropriated intervention benefit, particularly at home, may have accounted for the rather marginal reduction in their risky sexuality parameters, compared to the females, as depicted by the difference between their precedent and the current sexuality parameters, regardless of the suspected under- or exaggerated-reporting. As earlier noted the significantly poorer standing of males compared to the females with regards to having both parents being currently-alive may have influenced the comparative disadvantage of the males, in terms of the degree of home-related intervention-impact admittedly benefitted by them vis-à-vis their female counterparts.

The cross-analysis of the perceived impact of the two constituencies, combining the two genders show that the home domain to which a greater proportion of females than males ascribed positive impact has a higher positive approval score than the school constituency to which the larger proportion of males ascribed positive impact. The follow-up analysis which employed the Students' t-test to analyze if the observed difference in the pattern of impact-ascription to the two constituencies is significant, shows that the higher impact-ascription differentials by the female to the home constituency is indeed significant.

Contrariwise, the difference in the pattern of relevance-ascription to the school constituency, which incidentally enjoyed higher preference rating by the males, was statistically insignificant. In other words, while the difference between the male and the females with respect to the perceived relevance of home constituency produced a statistically significant result, the observed difference between both genders with respect to the school constituency was highly insignificant. The implication of the two contrasting results is interesting. Specifically it shows that the difference in the perceived relevance of the 
schools intervention to which the males ascribed greater impact-influence, being statistically insignificant, may be validly described as either a chance or error occurrence. Conversely, the observed difference in the home domain where females reported a higher level of positive impact may not be so described. Rather, the greater approval rating ascribed by the females to that constituency, which is significant, may be reliably generalized as reflecting the true scenario between the entire adolescent male and female in the larger population. Conclusively, it shows a clear cut difference between the two genders to the advantage of the females.

\section{Conclusion}

The study set out primarily to fill observed gap with reference to the deficiencies in the typical study designs employed in the analysis of issues on adolescent risky-sexuality interventions since the advent of HIV/AIDS, focusing on Lagos state's schooling adolescents for analytical exemplification. The first question addressed by the research was to characterize the socio-demographic backgrounds of the adolescent population in order to determine the extent to which they exhibit significant convergence or divergence. The study proceeded to compare the precedent and the current risky-sexuality profiles of the adolescent population also by gender. It then compared the degree of the genders' exposure to the existing actors of sexuality intervention in the two constituencies. Following this, it cross-analyzed the categorical responses of the perceived impactrelevance of the two constituencies, first, combining both genders, and second, obtaining separate crossanalysis for male and female.

Essentially it examined the degree of correspondence or harmony between the way each gender ascribed impact-relevance to one constituency vis-à-vis the other. The study ended up by determining the extent to which the observed differences in the pattern and magnitude of perceived impact-ascription by both genders to the two constituencies are significantly different. On the first objective the study discovered that the number of variables which differentiate the genders were slightly more in number than those which harmonize them. The comparison of the precedent and current riskysexuality profiles shows that although risky-sexuality appears to have declined generally, male adolescents exhibit comparatively higher levels of 'at-risk' both in term of the number of contracted sex-inducing partners and sexual frequency.

Analysis of the relative exposure of the two genders to home- and school-based interventionactors shows that the male gender is generally under- served by both constituencies, except that the effect shows much more in the home constituency, where its poorer home-ascribed impact-score is significantly lower than that of the females.

A number of recommendations evolve naturally from this study's findings, which touch on how to improve on the level of adolescents' benefits from existing interventions as well as on further-research issues which should command attention in the context of the present analytical framework. First, the study observed that the relatively poorer access to the most relevant intervention agents both at home and at school appears to underlie the poorer adjustment of male to on-going risky sexuality intervention in the two domains. It is also likely that the same reason underlines the tendency by them to ascribe significantly-lower impact-relevance value to the home constituency vis-à-vis the females.

These findings and inferences underscore the need for both constituencies, particularly the home domain to re-evaluate the attention paid to the male gender in order to enhance the overall performance of both constituencies. The fact is that the capability of the female gender to sustain the acclaimed benefit from both constituencies of intervention would partly depend not only on how their male counterparts are deemed to be well integrated, but the extent to which the males acknowledged the genuineness of the intentions of the stakeholders in the two constituencies towards them. Likewise, greater effort would be needed to translate the current moderate level of schools constituency's female-admitted positive impact to higher levels of perceived impact. This may require some diagnostic checks on those that make up the active agents in schools to determine among others, the appeal and the relative effectiveness of their methods and or approaches both of which are beyond the scope of the present study.

Perhaps of greater relevance is the need to examine whether or not any form of association or correlation exist between the various adolescents' personal and parental backgrounds and their differential access to the existing constituencies' intervention actors. This study for example discovered that the proportion of females with both parents alive exceeds that of males by nearly $15 \%$. This seems to suggest that the possession of both parents alive may be impacting intervention relevance. However, the fact that the proportions of both genders who live with either or both parents are almost the same, shows that there might be other intervening factors besides the possession of both parents alive.

Answers to these questions which are outside the purview of this paper, would go a long way in 
determining the extent to which the use of segmentation, that is, grouping adolescent into more distinct homogenous groups may be necessary in order to enhance the impact of the intervention message to them. These are premises for further research on intervention assessment using the current framework to enhance the multi-dimensional feedback utility of intervention results than had been hitherto.

\section{References}

Adegbola, O., O. Babatola and J. Oni. (1995). Sexual Networking in Freetown Against the Background of the AIDS Epidemic. Health Transition Review 5 (Supplement): 8I-II 2.

Adegbola, O. and Babatola O. (1999). Premarital and Extramarital Sex in Lagos, Nigeria. The Continuing HIVIAIDS Epidemic in Africa. HTC, ANU., Canberra $19-44$

Aji, J., Aji, M.O., Ifeadike,C.O., Emelumadu, C Ubajaka, SA Nwabueze, UE Ebenebe, EC Azuike (20/3) Adolescent Sexual Behaviour and Practices in Nigeria: A Twelve Year Review Afrimedic Journal AJO, 4(I)

Akpabio, I., I., Michael C. Asuzu, M.C., Fajemilehin, B., R. and Ofi, A.B.(2009) Effects of School Health Nursing Education Interventions on HIV/AIDSRelated Attitudes of Students in Akwa Ibom State, Nigeria Journal of Adolescent Health, 44(2): I I8123.

Amazigo U, (1997) Sexual activity and contraceptive knowledge and use among in-school adolescents in Nigeria. International Family Planning Perspectives 23:28-33

Anochie I.C., Ikpeme EE. (200I) Prevalence of sexual activity and outcome among female secondary school students in Port Harcourt, Nigeria. African Journal of Reproductive Health;5:63-7.

Babatola, O. (20/2) International Population Mobility and the Risk to Sexual Health in Lagos, Nigeria: A Comparative Assessment of Lagos-based Circulatory and Non-circulatory traders, 252pps. LAP Publishers (Germany)

Berhan, Y. and Berhan, A., (2015) A Meta-Analysis of Risky Sexual Behaviour among Male Youth in Developing Countries, Hindawi Publishing Corporation. Article ID 58096I, 9 pages http://dx.doi.org/I0.I I55/20 I5/58096 I.

Biddlecom, A., Awusabo-Asare, Bankole, A.(2009) Role of Parents in Adolescent Sexual Activity And Contraceptive Use in Four African Countries International Perspectives on Sexual and Reproductive Health, 2009, 35(2):72-8I.

Booysen, F. le R., Bachmann, M., Matebesi, Z. \& Meyer, J. (2004) The Socio-Economic Impact of HIV/AIDS on Households in South Africa: Pilot
Study in Welkom and Qwaqwa, Free State Province; University of the Free State Centre for Health Systems Research \& Development

Caldwell, J.C., Orubuloye, I.O., and Caldwell, P. (1999) Obstacles to behavioural change to lessen the risk of HIV infection in the African AIDS epidemic, in Resistances to Behavioural Change to Reduce HIVIAIDS Infection. HTCANU, Canberra I I 3 - I 24

Clark S., Kabiru C., and Zulu E., (20I I) Do Men and Women Report Their Sexual Partnerships Differently? Evidence from Kisumu, Kenya International. Perspectives on Sexual Reproductive Health. 20II Dec; 37(4): I8I-190.

Crockett, Lisa J.; Raffaelli, Marcela; and Moilanen, Kristin L., "Adolescent Sexuality: Behavior and Meaning" (2003). Faculty Publications, Department of Psychology. Paper 245. Available at:http://digitalcommons.unl.edu/psychfacpub/245. [Accessed on 2/6/2016].

Helleve A, Flisher AJ, Onya H, Matthews C, Aaro LE, Klepp KI(20II). The association between students' perceptions of caring teacher and sexual initiation: a study among South African high school students. Health education research.26(5):847-58.

Howard, M. and McCabe, J. (1990) Helping teenagers postpone sexual involvement. Family Planning Perspectives, 22, 21-26.

Howard, M. and Mitchell, M. (1993) Preventing teenage pregnancy: some questions to be answered and some answers to be questioned. Pediatric Annals, 22, 109-I I 8.

Insight Health Consulting Limited (2009) Lagos State HIV/AIDS Epidemiology, Response and Policy Synthesis Lagos State AIDS Control Agency

Izugbara, C. O. (2005). The socio-cultural context of adolescent's notion of sex and sexuality in rural south eastern Nigeria Sexualities, 8, 600-6I7.

Johnson BT, Carey MP, Marsh KL, Levin KD, ScottSheldon LA. (2003) Interventions to reduce sexual risk for the human immunodeficiency virus in adolescents, 1985-2000: a research synthesis. Archives of pediatrics \& adolescent medicine. I57(4):38|-8.

Johnson BT, Scott-Sheldon LA, Huedo-Medina TB, Carey MP.(20II) Interventions to reduce sexual risk for human immunodeficiency virus in adolescents: a meta-analysis of trials, 19852008. Archives of pediatrics \& adolescent medicine. I65(I):77-84.

Kirby. D. (1992) School-based programs to reduce sexual risk-taking behaviors. Journal of School Health, 62. 280-287.

Lori A. J. Scott-Sheldon, Paige Walstrom, Abigail Harrison, Seth C. Kalichman, and Michael P. Carey, (20I3) Sexual Risk Reduction Interventions for HIV 
Prevention among South African Youth: A MetaAnalytic Review Curr HIV Res. II (7): 549-558.

Makinde, B.O. (2008) Social Environments, Sexual Networking and Adolescents' Heterosexual Relationship in Lagos Metropolis, International Journal of Educational Research International Journal of Educational Research Vol. 3 (I) 2007 pp. I27-I 34.

Mathews C, Aarø LE, Grimsrud A, Flisher AJ, Kaaya $\mathrm{S}$, Onya $\mathrm{H}$, Schaalma $\mathrm{H}$, Wubs $\mathrm{A}$, Mukoma W, Klepp KI (20I2) Effects of the SATZ teacherled school HIV prevention programme on adolescent sexual behavior: cluster randomized controlled trials in three sub-Saharan African sites, International Health (RSTMH)

National Coalition for Sexual Health (20/3) The Sexual Health of Youth in the United States:

An Audience Profile

Ogbuagu S. C. and Charles J. O. (1993) Survey of sexual networking in Calabar: Health Transition Review, Supplement to vol. 3, 105-119

Paul-Ebhohimhen VA, Poobalan A, van Teijlingen ER.(2008) A systematic review of school-based sexual health interventions to prevent STI/HIV in sub-Saharan Africa. BMC Public Health. 2008; 8:4
Ryckman, R.M. (2008). Theories of Personality. Thomson Wadsworth: Belmont.

Santelli, J.S., Lowry, R., Brener, N.C., and Robin, L, (2000) The Association of Sexual Behaviors With Socioeconomic Status, Family Structure, and Race/Ethnicity Among US Adolescents American Journal of Public Health October 2000Taraphdar, P., Rray T.,. Guha, D., Haldar, A., Chatterjee, A., Dasgupta, B., Saha,S. and Mallik, Vol. 90, No. 10 pp. $1582-1588$.

Stevens, R., \& Cloete, M.G.T. (2009). Introduction to criminology. (6th edition). Oxford University press: Cape Town

S.(20II) Socioeconomic consequences of HIV/AIDS in the family system Niger Med J. 52(4): 250 253.

Timko, J. (20I I) HIV/AIDS, Forests and Futures in Sub-Saharan Africa, STEPS Working Paper 43, Brighton: STEPS Centre

USAID (2013) Knowledge, Attitude \& Practice (KAP) Baseline Assessment Final Report: Healthy Outcomes through Prevention Education (HOPE) program 